\title{
Relationships Among Alcohol Outlet Density, Alcohol use, and Intimate Partner Violence Victimization Among Young Women in the United States
}

\author{
Martha W. Waller ${ }^{1}$, Bonita J. Iritani ${ }^{1}$, Sharon L. Christ ${ }^{2}$, Heddy Kovach Clark ${ }^{1}$, Kathryn E. \\ Moracco $^{3}$, Carolyn Tucker Halpern ${ }^{3}$, and Robert L. Flewelling ${ }^{1}$ \\ ${ }^{1}$ Pacific Institute for Research and Evaluation, Chapel Hill, NC, USA \\ ${ }^{2}$ Department of Human Development and Family Studies and Department of Statistics, Purdue \\ University \\ ${ }^{3}$ Gillings School of Global Public Health, University of North Carolina at Chapel Hill
}

\section{Abstract}

Greater access to alcohol has been widely found to be associated with many negative outcomes including violence perpetration. This study examines the relationship between alcohol outlet density, alcohol use, and intimate partner violence (IPV) victimization among young women in the United States. A direct association between alcohol outlet density in one's neighborhood and the likelihood of IPV victimization was examined. Data were from Wave III of the National Longitudinal Study of Adolescent Health (Add Health), which followed a nationally representative sample of adolescents into adulthood. Participants were young adult females age 18 to 26 at Wave III. Of the 4,571 female respondents who reported a current heterosexual relationship and had IPV data, $13.2 \%$ reported having been the victim of physical violence only and $6.5 \%$ experienced sexual only or physical and sexual violence in the relationship during the past year. In the regression models tested, there was no significant direct association between neighborhood alcohol outlet density and IPV victimization nor was there an association between outlet density and drinking behaviors, thus eliminating the possibility of an indirect association. Results of fully adjusted models indicate females who drank heavily, whether infrequently or frequently, were at significant risk for experiencing sexual only IPV or sexual and physical IPV. Asians and Native Americans were at significantly greater odds of experiencing sexual only or sexual and physical IPV compared with non-Hispanic Whites, while non-Hispanic Blacks were at significantly greater odds for physical only IPV. We conclude that a continuous measure of alcohol outlet density was not associated with IPV in models controlling for individual and other neighborhood characteristics. Young women who drink heavily, whether infrequently or frequently, have greater odds of experiencing sexual only or sexual and physical compared to abstainers. Similar to previous study findings, young women living with or married to their partner were at far greater risk of experiencing physical only and/or sexual only or sexual and physical IPV. The study adds to the growing body of literature that examines how community characteristics such as outlet density influence the likelihood of IPV.

\section{(C) The Author(s) 2011}

Corresponding Author: Martha W. Waller, Associate Research Scientist, Pacific Institute for Research and Evaluation, 1516 E. Franklin Street, Suite 200, Chapel Hill, NC 27514-2812, USA, mwaller@PIRE.org.

Authors' Note

Information on how to obtain the Add Health data files is available on the Add Health web site (http://www.cpc.unc.edu/addhealth) No direct support was received from grant P01-HD31921 for this analysis.

Declaration of Conflicting Interests

The author(s) declared no potential conflicts of interest with respect to the research, authorship, and/or publication of this article. 


\section{Keywords}

intimate partner violence; alcohol outlet density; neighborhoods; young adulthood; drinking; alcohol use

Strong positive correlations between alcohol use and intimate partner violence (IPV) as well as associations found between alcohol outlet density and other types of violence have led researchers to examine if greater access to alcohol is also associated with violence between intimate partners (Cunradi, 2010; Cunradi, Mair, Ponicki, \& Remer, 2011; Livingston, 2010, 2011; McKinney, Caetano, Harris, \& Ebama, 2009). This study examines whether increases in alcohol outlet density are associated with increases in the likelihood of being victimized by an intimate partner among a nationally representative sample of young adult women. We examine whether outlet density has a direct association with IPV victimization by contributing to more tolerant norms toward violence and the lowering of constraints on violence and an indirect association by changing drinking patterns and increasing problem drinking among at-risk couples. Findings from this study will improve our understanding of the roles of alcohol outlet density and alcohol use on IPV victimization. Results from this study can also provide guidance on how policies that address issues of land use to modify the environment may affect the occurrence of IPV thus providing public policy experts, public health practitioners, and community leaders alternate strategies for addressing the public health problem of intimate partner violence. In addition, this study will help to further develop and evaluate an ecological model of IPV among young adults.

Numerous studies have found that greater alcohol consumption among male perpetrators was associated with a greater number of interpersonal violent acts and more severe IPV than violent episodes without alcohol consumption and that alcohol use by the perpetrator increases the likelihood of injury (Foran \& O'Leary, 2008; Graham, Bernards, Wilsnack, \& Gmel, 2011; McKinney, Caetano, Rodriguez, \& Okoro, 2010). On the other hand, there is conflicting evidence that higher alcohol consumption among women is associated with greater victimization by a male partner (McKinney et al., 2010; Thompson \& Kingree, 2006). Nevertheless, the strong association with alcohol use and IPV in general, have led researchers to examine whether greater access to alcohol, as measured by alcohol outlet density, is also associated with intimate partner violence either by increasing alcohol consumption or by influencing the environment.

Several studies have reported a relationship between the density of alcohol outlets and negative behavioral outcomes, such as higher levels of alcohol consumption among youth and adults, and a greater prevalence of alcohol-related crime, violence, and injury (Gruenewald et al., 2010; Gruenewald, Freisthler, Remer, LaScala, \& Treno, 2006; Livingston, 2008; Popova, Giesbrecht, Bekmuradov, \& Patra, 2009). At a neighborhood level, Cunradi (2010) and Caetano and colleagues have suggested that alcohol outlet density may be directly associated with intimate partner violence (IPV) because outlets may be a signal of lowered normative constraints regarding violence within the neighborhood, promote problematic drinking in at-risk couples living in the neighborhood, and provide an environment that facilitates more tolerant IPV attitudes and norms, and IPV behaviors (Caetano, Ramisetty-Mikler, \& Harris, 2010; Cunradi, 2010). At an individual level, increased alcohol outlet density has been shown to increase alcohol consumption and problem drinking behavior, which in turn have been found to be associated increases in IPV (Campbell et al., 2009) implying that outlet density affects drinking at an individual level. 1

${ }^{1}$ For a review of multiple theoretical models proposed as to why alcohol outlet density and IPV are related, see Gruenewald (2007) and Cunradi (2010). 
Despite plausible causal mechanisms, as well as extant evidence that alcohol use is highly associated with IPV perpetration and victimization, to our knowledge, relatively few published studies have examined the association between alcohol outlet density and IPV (Cunradi et al., 2011; Gorman, Labouvie, Speer, \& Subaiya, 1998; Livingston, 2010, 2011; McKinney et al., 2009). The current study uses data from the National Longitudinal Study of Adolescent Health (Add Health) to investigate the relationships between alcohol outlet density, alcohol use, and intimate partner violence victimization among young women in the United States.

\section{Alcohol Outlet Density and Intimate Partner Violence}

Almost all of the prior research on alcohol outlet density and IPV have been ecological studies in which groups of people rather than individuals are examined as the unit of analysis. Gorman and colleagues (Gorman et al., 1998) found no association between alcohol availability and IPV among 223 large municipalities in New Jersey. One explanation for the lack of association could be related to the large geographic areas being studied. Research has since found that smaller geographic units such as census tracts or block groups are more homogenous and better represent neighborhoods and their effects on behavior than do cities, counties, or other large geographic units (Gruenewald, Millar, \& Roeper, 1996; Millar \& Gruenewald, 1997; Scribner, Cohen, Kaplan, \& Allen, 1999). In addition, such area-based studies need to use specialized geospatial statistical techniques, which correct for correlations between adjacent geographic units, to study this relationship, which were not used in Gorman et al.'s (1998) study. 2 Cunradi et al. (2011) found a significant positive association between off-premise alcohol outlet density and IPV-related police calls and crime reports among smaller geographic areas averaging 0.17 square miles in size, in Sacramento, California. Livingston (2010) found that alcohol outlet density, specifically hotels and pubs, was positively associated with domestic violence rates but outlet density of restaurants and bars was negatively associated with domestic violence based on aggregate police-recorded domestic violence rates stratified by postal code in Melbourne, Australia and (Livingston, 2010). However, additional longitudinal examination of the data found a significant positive relationship between all three types of outlet license density (general [pub], on-premise, and packaged liquor licenses) with domestic violence rates (Livingston, 2011). Using police and crime report data, however, has limitations. Identifying IPV through Uniform Crime Reports (UCR) and police calls includes only incidents reported to law enforcement. As most IPV goes unreported, this is likely an underrepresentation of IPV (Gorman et al., 1998). Also, police call data may possibly include multiple calls per event (Cunradi et al., 2011). Finally, crime report data lack important individual-level information about the individuals' demographic and behavioral characteristics such as the victim's biological sex and drinking behavior. In contrast to the ecological studies, McKinney and colleagues (2009) found a significant positive association between alcohol outlet density at the zip code level and male-to-female partner violence among a national population-based sample of 1,597 married or cohabiting couples (McKinney et al., 2009). Furthermore, the association was even stronger among couples with alcohol-related problems, for example, alcohol dependence characteristics and consequences of alcohol dependency such as work or financial problems.

\section{Present Study and Conceptual Model}

The present study advances previous research by examining smaller geographical units (i.e., census tract) than used by McKinney et al. (2009) and Gorman et al. (1998). Although like McKinney and colleagues, we used self-reports of IPV victimization rather than only cases

\footnotetext{
${ }^{2}$ See Gruenewald, Millar, Ponicki, and Brinkley (2000) for a discussion of these methods.
} 
reported to law enforcement and we used a national probability sample. Compared with McKinney and colleagues study (2009) our sample size is considerably larger and we include data for the large segment of individuals who have an intimate partner but who are not married or cohabiting. Add Health is a unique and excellent data source for investigating the present research topic. It contains census tract-level data on alcohol outlet density and other neighborhood characteristics as well as information about the individual respondents reporting about their relationships and alcohol use. Furthermore, by using a stratified nationally representative sample as the unit of analysis instead of area units, problems associated with analyzing spatial data are less of a concern. Specifically, individuals are spread across spatial areas meaning that they are less likely to be clustered within locations or located in adjacent areas. Thus spatial autocorrelation (i.e., correlations that arise between adjacent units) is minimized (Alaniz, Cartmill, \& Parker, 1998; Freisthler, Lery, Gruenewald, \& Chow, 2006; Gruenewald et al., 2000).

Given the links between outlet density and alcohol use, as well as alcohol use and IPV, we tested a conceptual model that includes drinking behavior as a mediator of the relationship between alcohol outlet density and IPV. We hypothesized that alcohol outlet density at the census tract level would be both directly and indirectly associated with IPV among women reporting IPV victimization from opposite-sex partners. Figure 1 presents our overall conceptual model.

\section{Method}

\section{Sample}

Data were from Wave III of the National Longitudinal Study of Adolescent Health (Add Health), which was conducted in 2001-2002 when respondents were approximately 18 to 26 years old $(N=14,322)$. Add Health is a prospective cohort study that has followed a nationally representative sample of U.S. adolescents into young adulthood. Its original sample was drawn from 7th- to 12th-grade students on school enrollment rosters in 19941995. A sample of 80 high schools and 52 middle schools was selected with unequal probability of selection. Incorporating systematic sampling methods and implicit stratification, in which sampling units are first sorted by characteristics before systematically sampling, into the study design ensured that selected schools were representative of U.S. schools with respect to region of country, urbanicity, school size, school type, and ethnicity. Additional information about the Add Health survey design is available elsewhere. (Harris et al., 2009)

For Wave III, researchers sought to interview all original study participants living in the United States, including homeless and incarcerated individuals. The response rate for Wave III was 77.4\%. (Chantala, Kalsbeek, \& Andraca, 2003; Harris et al., 2009) A total of 8,463 of the 14,322 respondents with the Wave III cross-sectional sampling weight reported at least one current relationship. Present analyses were based on female respondents in the Wave III nationally representative sample with at least one reported current relationship. To manage the complexity of the data (multiple relationships could be reported by respondents), only one current relationship per respondent was used in analyses. To approximate a random sample of relationships, we chose to use the relationship that happened to have the lowest relationship ID number. Respondents whose identified relationship was with a same-sex partner represented a very small percentage (1.4\%) and were excluded from analyses. A total of 4,571 young women had an identified relationship and nonmissing data on the IPV outcome variable.

Participants provided written consent to be interviewed and questionnaires were administered via laptop computer. Computer-assisted self-interviewing (CASI) technology 
was used to inquire about sensitive topics, including sexual, substance use, and violence behaviors. The University of North Carolina at Chapel Hill Institutional Review Board (IRB) approved all study procedures for Add Health. Present analyses were approved by the Pacific Institute for Research and Evaluation IRB.

\title{
Measures
}

Intimate partner violence (IPV) victimization-The IPV outcome was based on the survey items "How often in the past year has <PARTNER> threatened you with violence, pushed or shoved you, or thrown something at you that could hurt?" "How often in the past year has <PARTNER> slapped, hit, or kicked you?" and "How often in the past year has $<$ PARTNER> insisted on or made you have sexual relations with [HIM/HER] when you didn't want to?" Responses were dichotomized (never or hasn't happened in past year versus happened one or more times in past year). A 3-category nominal variable was created indicating type of IPV victimization experienced in the past year in the relationship, (0) physical IPV only, (1) sexual IPV only or both physical and sexual IPV, and (2) no IPV (referent category).

Alcohol outlet density in neighborhood-Data were obtained for number of alcohol outlets (establishments possessing on- and/or off-premise alcohol licenses) per square kilometer for Wave III respondent communities. Alcohol outlet licensing data were gathered from individual states during 2006-2007. While these data were collected 5 to 6 years after the IPV data, alcohol outlet density in small geographic areas is a relatively stable measurement over time (Gruenewald \& Remer, 2006). The outlet addresses were geocoded and then aggregated to the census tract-level. Using census tracts is a standard and wellregarded method of measuring neighborhood contexts (Cubbin, Brindis, Jain, Santelli, \& Braveman, 2010; Krieger, Chen, Waterman, Rehkopf, \& Subramanian, 2003). Census tracts contain an average of 4,000 individuals and are designed to be "as homogenous as possible with respect to population characteristics, economic status, and living conditions" (U.S. Dept of Commerce Bureau of the Census, 1994, p. 10-1). The median alcohol outlet density in study participants' tracts was 0.76 outlets per square kilometer. The variable was Winsorized to address skewness by recoding extreme outliers at the tail ends to be equal to a cutoff value (National Institute Standards and Technology [NIST], 2007). We recoded values that were greater than three times the standard deviation to be the value corresponding to the third standard deviation. A dichotomized version of the variable was used in some of the analyses. This variable was created after examining the probability curve for density and was coded (0) less than the 90th percentile of the alcohol outlet density variable ( $<7.57$ outlets per square kilometer), or (1) the 90th percentile or higher $(\geq 7.57$ outlets per square kilometer). On-premise and off-premise density measures were examined separately in initial analyses, but results indicated no difference in the ability to predict IPV or alcohol consumption between the two types of outlet measures and therefore were collapsed.

\begin{abstract}
Alcohol use-Several dimensions were incorporated in the alcohol use measure: ever drinking alcohol, drinking in the past 12 months, frequency and quantity of drinking in past 12 months, binge drinking in past 2 weeks, and having been drunk in past 12 months. A 6category nominal variable for alcohol use was created and coded as follows: (a) lifetime abstainer or former (but not current) drinker, (b) light drinker, (c) moderate drinker, (d) infrequent heavy drinker, (e) occasional heavy drinker, and (f) frequent heavy drinker. Table 1 defines each of the 6 categories.
\end{abstract}

Control variables-Age was measured in years. Race/ethnicity, based on respondent selfreport, was Hispanic (of any race) and non-Hispanic categories of White, Black, Asian or 
Pacific Islander, and Native American. For multiracial participants, the category they said best described their racial background was used. Marital status of the reference relationship was represented by these categories: never married or never lived with this partner (referent category), lived with this partner but never married partner, or ever married to this partner. Three variables were measures of the respondent's recollection of a parent or other adult caregiver's behavior before the respondent was in 6th grade with respect to (a) neglect (left respondent home alone when an adult should have been present or did not take care of respondent's basic needs), (b) "slapped, hit, or kicked" the respondent, and (c) sexual abuse of the respondent, defined as a positive response to having had an adult touch them in a sexual way, forced them to touch him or her in a sexual way, or forced them to have sexual relations. All three of the neglect/abuse measures were dichotomized as $0=$ never, $1=$ ever .

Several neighborhood-level sociodemographic characteristics were included as control variables. These contextual variables used tract-level data from the census (Census of Population and Housing, 2000: Summary File 3; Swisher, 2008) and are measures of (a) poverty (an index of the average of the standardized estimates for the unemployment rate, proportion of persons below the poverty level, and proportion of families with a child in a female-headed household; Cronbach's $a=.72$ ), (b) transience (an index reflecting the average of the standardized estimates for the proportion of the population who had moved in the past 5 years and the proportion of occupied units that were renter-occupied; Cronbach's $a=.82$ ), (c) proportion of residents who were foreign born, and (d) proportion of housing units vacant (Swisher, 2008). Items chosen for the indices were based on factor analysis (principal components) results, which indicated unemployment, poverty level, and families with children in female-headed households were highly correlated with one factor (factor loadings $=0.78,078$, and 0.71, respectively), and moving in the past 5 years and renteroccupied units being correlated with another factor $(0.93$ and 0.83 ). Proportion foreign born and proportion housing units vacant were retained as single-item variables. In addition, we created dichotomous measures for each census tract measure to examine bivariate associations. Proportions at the 90th percentile or above were categorized as high while anything below the 90th percentile was categorized as low/moderate. This cutoff was used to identify tracts strongly indicating the selected sociodemographic characteristic when conducting analyses stratified by the characteristic.

\section{Analyses}

First, bivariate relationships among alcohol outlet density, alcohol use, and IPV victimization (density predicting IPV, density predicting drinking, and drinking behavior predicting IPV) were examined.

Multinomial logistic regression with IPV victimization as the dependent variable and no IPV victimization as the referent category was used. This analysis examined two models: (a) alcohol outlet density and alcohol use directly predicting IPV victimization, and (b) alcohol outlet density predicting alcohol use. In addition, models using alcohol outlet density and alcohol use to predict IPV victimization were conducted stratified by several demographic characteristics (respondent older than 22 years or not, respondent in tract with high proportion vacant housing, respondent in tract with high proportion foreign born, respondent in tract with high proportion transience, and respondent in tract with high proportion in poverty). Both unadjusted regressions and regressions adjusted for individual-level control variables and individual-level plus community-level control variables were estimated. Multilevel modeling was not used for community-level variables (alcohol outlet density and census measures) because there were few census tracts in which more than one Add Health study participant resided, and data were not sufficiently nested (Cubbin et al., 2010; Cubbin, Santelli, Brindis, \& Braveman, 2005) and therefore, measures at the neighborhood level were treated as individual level measures. Additional models examining the curvilinear 
relationship between outlet density and IPV victimization were tested. Finally, structural equation modeling was conducted to find whether or not alcohol use was a mediator of the relationship between alcohol outlet density and IPV.

Poststratification sampling weights were used to yield estimates representative of the national population. Analyses were conducted using SAS (SAS, 9.13, Cary, NC) and MPlus (Version 6, Muthén \& Muthén, 1998-2010, Los Angeles, CA). Procedures for survey data in Mplus accounted for Add Health's complex sampling design in regression models. All reported percentages are weighted percentages; sample sizes are unweighted.

\section{Results}

Among the female respondents at Wave III, $64.5 \%(N=4,810)$ had a current, heterosexual relationship with nonmissing corresponding IPV victimization data. Among these young women, $13.2 \%$ reported they had been the victim of physical violence in the past year in the identified relationship, 6.5\% reported experiencing either sexual only or physical and sexual violence in the relationship in the past year, and $80.3 \%$ reported not having been the victim of violence in the relationship in the past year. Table 2 shows characteristics of the sample of young women with nonmissing data on sociodemographics, alcohol use, and IPV. The final sample of women who identified an opposite-sex relationship and no missing data was $(N=4,432)$.

\section{Bivariate Analyses}

In this sample of young women, there was a not significant relationship found in the bivariate relationship between alcohol outlet density and IPV victimization $(\mathrm{OR}=1.00, n s$ for predicting physical only IPV vs. no IPV and OR $=1.00$, $n s$ for predicting sexual only or physical and sexual IPV vs. no IPV). Alcohol outlet density was not associated with membership in any of the alcohol use categories in comparison to being an abstainer (ORs ranged from 0.99 to $1.00, n s$ ). However, bivariate analyses indicated that infrequent heavy drinking was significantly associated with greater likelihood of being a victim of sexual only or physical and sexual IPV versus not having experienced IPV (OR $=1.61, p<.05)$. Otherwise, drinking was not found to be associated with IPV victimization (ORs ranged from 1.06 to $1.59, n s)$. Alcohol use was associated with IPV only among females living in tracts with the highest alcohol outlet densities (i.e., top 90th percentile, $>7.57$ outlets per square kilometer). Light drinkers $(\mathrm{OR}=2.64, p<.05)$ and frequent heavy drinkers $(\mathrm{OR}=$ $6.24, p<.01$ ) were more likely than abstainers to have experienced sexual only or physical and sexual IPV victimization. However, moderate drinkers were less likely than abstainers to be the victim of physical IPV ( $\mathrm{OR}=0.26, p<.01$ ) or sexual only or physical and sexual $\mathrm{IPV}(\mathrm{OR}=0.10, p<.01)$.

\section{Adjusted Models of Outlet Density and Drinking Predicting IPV}

Alcohol outlet density was not a significant predictor of IPV victimization type in any of the three models (see Table 3). Furthermore, alcohol use was not found to be associated with physical IPV in any of the three models. However, infrequent heavy drinking was significantly associated with elevated odds of sexual only or physical and sexual IPV victimization in Model 2 (which added individual controls) and Model 3 (which added individual and community level controls). In Model 3, where all controls were included, frequent heavy drinkers also showed increased odds of sexual only or physical and sexual IPV victimization. Several control variables were found to be significantly associated with IPV victimization in Model 3. Compared to non-Hispanic Whites, Blacks were more likely to have experienced physical IPV only, and Asians and Native Americans were more likely to have experienced sexual only or physical and sexual IPV. Both cohabitation and marriage 
to a partner were associated with greater odds of IPV compared to never marrying the partner. Physical abuse as a child was also associated with greater likelihood of victimization. Neighborhood transience was associated with reduced likelihood of experiencing physical IPV, while neighborhood poverty was associated with greater likelihood of experiencing sexual only or physical and sexual IPV victimization.

\section{Models of Outlet Density Predicting Drinking}

Alcohol outlet density was not a significant predictor of being in any of the alcohol use categories in either the unadjusted model (ORs ranged from 0.99 to 1.01, $n s$, not shown in table), the model with individual-level covariates (ORs ranged from 0.99 to $1.01, n s$ ), or the model with all covariates (ORs ranged from 0.99 to $1.02, n s$ ). In addition, outlet density was not found to be related to IPV victimization. Therefore, additional structural equation model analyses were not conducted to examine alcohol use as a potential mediator.

\section{Discussion}

To date, only five published studies have attempted to directly examine how the physical availability of alcohol may be associated with IPV. This study built on previous research by assessing alcohol outlet density using a smaller geographical area and a self-reported measure of victimization from a study with a large nationally representative sample of young women. Although we used smaller geographic units, as has been recommended, and self-reports of IPV victimization in our analysis, like Gorman and colleagues' (Gorman et al., 1998) we found no association between access to alcohol as measured by alcohol outlet density and IPV victimization in unadjusted or adjusted models. There also was no significant association when data were examined stratified by on-premise or off-premise outlet density. It is unclear why our findings conflict with those of McKinney et al. (McKinney et al., 2009). It is possible that among adult populations with available transportation, census tracts are actually too small a geographic area and that a wider area such as zip code, which McKinney and colleagues used, is more reflective of true alcohol availability. Alternatively, perhaps census tracts are still too large. Schonlau and colleagues (2008) found that even smaller geographic units, that is, within a 1 mile radius of respondent, were better predictors of alcohol consumption than outlet density at a census tract level (Schonlau et al., 2008). Gorman and colleagues on the other hand likely did not find an association most likely because the assessment of IPV was based on UCR data and not self-reports. In our study, only in unadjusted models, did females in the highest outlet density tracts (i.e., 90th percentile, > 7.57 outlets per square kilometer) show any increased risk for IPV. Interestingly, this risk increased further, if the high outlet density also occurred within a high vacancy tract. Therefore, while our continuous measure of outlet density was not significantly associated, we found our measure of high outlet density, was associated with increased odds of IPV victimization, indicating that the threshold for association is relatively high.

As in previous studies, we found that alcohol consumption was associated with female IPV victimization (Foran \& O’Leary, 2008; Graham et al., 2011; McKinney et al., 2010). Our measure of alcohol use incorporated both the frequency of drinking and quantity consumed at one time rather than relying on a single feature of drinking or examining two separate measures as most studies use. As such we were able to distinguish between light and heavy drinkers and frequent and infrequent drinkers. Infrequent and frequent heavy drinkers appear to be at considerably greater risk for experiencing sexual only or physical and sexual IPV than abstainers of alcohol. It is not clear why occasional heavy drinkers are not at elevated risk of IPV. We speculated that greater variance in IPV among occasional heavy drinkers might explain the absence of an association. To test this, we calculated the index of qualitative variation or IQV, a measure of statistical dispersion for categorical measures, for 
the outcome, IPV, within each drinking category and compared results. However, there was essentially no difference in the IQV estimates that would explain why the most prevalent drinking category is nonsignificant while the categories on either side are.

Present results would suggest that it is not heavy drinking per se that is related to IPV but rather the frequency of heavy drinking. Yet ORs for heavy drinkers in Models 2 and 3 were all greater than 1 , and while not statistically significant, suggests a similar trend.

Many individual level measures controlled for in our analyses were also significantly associated with IPV supporting findings from previous studies. In particular, in the final adjusted model, respondents in married or cohabitating relationships were at considerable increased risk for physical IPV only. This increased risk reflects the increased exposure inherent in cohabitating situations and is supported by previous research by Brown and Bulanda (2008; Brown \& Bulanda, 2008), which similarly found that cohabitators and married couples were more at risk for IPV than daters and cohabitators were most at risk. However, Brown and Bulanda's (2008) hypothesis that lower commitment in cohabitating relationships would explain the increase in IPV was not supported. Our results also showed experiencing physical abuse as a child to be significantly associated with both physical IPV victimization and sexual IPV victimization among young adult women. These findings are congruent with past research (Gomez, 2011; Gover, Kaukinen, \& Fox, 2008) and the cycle of violence hypothesis (Heyman \& Slep, 2002). Previous research has found a differential association between race/ethnicity and IPV mostly among Blacks, and Hispanics when compared with non-Hispanic Whites (Caetano, Ramisetty-Mikler, \& Harris, 2008; Caetano, Schafer, \& Cunradi, 2001). In our study sample, race/ethnicity was also associated with increased risk for physical only IPV and sexual only or physical and sexual IPV, but the patterns were somewhat different. For physical only IPV, non-Hispanic Blacks were at increased risk when compared to non-Hispanic Whites. Yet there were no significant increase in odds of physical only IPV among Hispanics, Asians, or Native Americans when compared to non-Hispanic Whites. On the other hand, when sexual or sexual and physical IPV is the outcome, non-Hispanic Asians and Native Americans have much higher odds compared to non-Hispanic Whites while non-Hispanic Blacks and Hispanics were not statistically different from non-Hispanic Whites. It interesting that among young women there is varying risk between race/ethnicity and different types of IPV victimization and future research should examine the mechanisms through which race/ethnicity is related to varying types of IPV. Specifically, does race/ethnicity in some way affect or predict the context or cultural norms within which IPV occurs and therefore, influences the type of IPV experienced? Understanding how race/ethnicity may indirectly affect IPV occurrence and type can be useful in tailoring IPV prevention programs and programs for victims as well, so that information about relevant context can be used to best help victims and potentially reduce racial disparity in IPV victimization.

Several census tract-level measures were included in these analyses to control for other neighborhood characteristics that may be correlated with both outlet density and violence. Sampson et al. (1997) found that neighborhood measures of concentrated disadvantage, immigrant concentration, and residential stability explained $70 \%$ of the variation in a measure of neighborhood collective efficacy which, in turn, mediated the relationship between neighborhood disadvantage and stability and measures of violence. (Sampson, Raudenbush, \& Earls, 1997) The present research found that two census tract measures were significantly associated with female victimization in the final adjusted model. Neighborhood transience was negatively associated with physical only IPV $(\mathrm{AOR}=.99,95 \% \mathrm{CI}=[0.986$, 0.997], $p<.05$ ); neighborhood poverty was positively associated with sexual only or physical and sexual only IPV $(\mathrm{AOR}=1.01,95 \% \mathrm{CI}=[1.002,1.023], p<.05)$. Given that these odd ratios are close to 1.0, caution should be used regarding these findings. However, 
it should be noted that the census tract measures are continuous measures with many values; therefore, incremental change is very small. Our finding regarding neighborhood poverty is in keeping with Cunradi et al. (2000) who found a significant increase in the risk for IPV perpetration in couples living in impoverished neighborhoods. (Cunradi, Caetano, Clark, \& Schafer, 2000) However, it contrasts with that of Caetano et al. (2010) who found no effect of census tract-level poverty, defined simply as the percentage of the tract's population below the poverty line, either directly or indirectly on IPV after the effects of drinking measures and demographics were controlled. (Caetano et al., 2010) Our results indicate percent foreign-born and percent vacant housing in one's neighborhood were not significantly associated with IPV. However, we note that the 2.79 adjusted odds ratio associated with neighborhood foreign-born had a large $95 \%$ confidence interval $[0.565$, 13.79].

One explanation for the lack of association frequently found between alcohol outlet density and other tract-level measures and IPV has been proposed in work by Caetano and colleagues.(Caetano et al., 2010) They argue that most research examining the correlation between outlet density and neighborhood characteristics and violence, has found significant associations. However, most of this research has focused on violence that occurs outside the confines of the home, that is, in public. IPV is somewhat unique in that it occurs behind closed doors in privacy. Alcohol outlet density as well as other neighborhood characteristics may be more strongly associated with violence that occurs outside the home rather than inside and the mechanisms that affect IPV may be different from those that affect violence per se. Alternatively, our measure of alcohol density, defined as outlets per square kilometer of census tract, may have precluded our ability to find significant associations between density and IPV. While our measure of density is at a smaller geographic region than many previously used such as zip code, municipalities, or city-level density, other non-IPV-related studies have looked at outlets per roadway mile, which takes into account the actual accessibility of the outlets and may have better predictive ability. Greater specificity of this measure to the respondent would likely result in a stronger indicator and a greater likelihood of detecting more subtle effects of alcohol outlet density on IPV.

\section{Limitations}

There are additional limitations to this study. Although Add Health is a longitudinal study, the current analyses are based on cross-sectional data from Wave III, thus limiting conclusions regarding directionality of relationships. Furthermore, Add Health did not assess whether IPV and alcohol use co-occurred. Thus, while a global association between outlet density and IPV may exist, it does not necessarily mean that alcohol use was involved during a specific IPV event. A key limitation is the absence of alcohol use measures for the respondents' partners. A more complete conceptual model would include alcohol use by both the respondent and her partner, as previous research indicates that use by both persons exacerbates the likelihood of IPV. The impact of this limitation is that any direct effect of outlet density could be due in part to the mediating (but unmeasured) influence of the partner's alcohol use. However, in this study, we found no direct effects of outlet density. Finally, Wave III of Add Health is limited to young adults 18 to 26 years old. Both IPV and alcohol consumption have been found to decrease with age, therefore these findings may not be generalizable to older adults.

\section{Conclusions}

Our hypothesis that alcohol outlet density, either on-premise or off-premise, would both directly and indirectly affect IPV victimization among women was not supported. However, we did find in this nationally representative sample that heavy drinking among young women, whether infrequent or frequent, increases the risk of sexual or sexual and physical 
victimization to over twice the risk of nondrinkers. The unexpected finding of nonsignificant results among occasional heavy drinkers, bears further research.

In 2010, Cunradi (Cunradi, 2010) called for more research on understanding the mechanisms through which community characteristics affect IPV. Our study adds to the growing body of literature that examines community characteristics and IPV and contributes to the development of an ecological model of IPV among young adults. Improving on previous research, we examined a nationally representative sample of young women who self-reported IPV victimization and used smaller geographic units of outlet density. To more fully understand the relationship, future research should include alcohol outlets in neighborhoods adjacent to and surrounding each neighborhood to measure more fully the availability of alcohol to residents as well as partner drinking behaviors, and context of IPV. In addition, research should examine whether the influence of community characteristics differ by sex and by type of IPV. Our findings may be used to advise liquor license management, public policy, and prevention strategies.

\section{Acknowledgments}

This research uses data from Add Health, a program project directed by Kathleen Mullan Harris and designed by J. Richard Udry, Peter S. Bearman, and Kathleen Mullan Harris at the University of North Carolina at Chapel Hill, and funded by grant P01-HD31921 from the Eunice Kennedy Shriver National Institute of Child Health and Human Development, with cooperative funding from 23 other federal agencies and foundations. Special acknowledgment is due Ronald R. Rindfuss and Barbara Entwisle for assistance in the original design.

\section{Funding}

The author(s) disclosed receipt of the following financial support for the research, authorship, and/or publication of this article: Funding for this study is from the National Institute for Alcohol and Alcohol Abuse (R03AA016809, MWW, principal investigator).

\section{References}

Alaniz ML, Cartmill RS, Parker RN. Immigrants and violence: The importance of neighborhood context. Hispanic Journal of Behavioral Sciences. 1998; 20:155-174.

Brown SL, Bulanda JR. Relationship violence in young adulthood: A comparison of daters, cohabitors, and marrieds. Social Science Research. 2008; 37(1):73-87.

Caetano R, Ramisetty-Mikler S, Harris TR. Drinking, alcohol problems and intimate partner violence among White and Hispanic couples in the U.S.: Longitudinal associations. Journal of Family Violence. 2008; 23:37-45.

Caetano R, Ramisetty-Mikler S, Harris TR. Neighborhood characteristics as predictors of male to female and female to male partner violence. Journal of Interpersonal Violence. 2010; 25:19892009.

Caetano R, Schafer J, Cunradi CB. Alcohol-related intimate partner violence among White, Black, and Hispanic Couples in the United States. Alcohol Research \& Health. 2001; 25(1):58. [PubMed: 11496968]

Campbell CA, Hahn RA, Elder R, Brewer R, Chattopadhyay S, Fielding J, Middleton JC. The effectiveness of limiting alcohol outlet density as a means of reducing excessive alcohol consumption and alcohol-related harms. American Journal of Preventive Medicine. 2009; 37:556569. [PubMed: 19944925]

Chantala K, Kalsbeek WD, Andraca E. Non-response in Wave III of the Add Health study. 2003 Retrieved from http://www.cpc.unc.edu/projects/addhealth/files/analyze.pdf.

Cubbin C, Brindis CD, Jain S, Santelli J, Braveman P. Neighborhood poverty, aspirations and expectations, and initiation of sex. Journal of Adolescent Health. 2010; 47:399-406. [PubMed: 20864010] 
Cubbin C, Santelli J, Brindis CD, Braveman P. Neighborhood context and sexual behaviors among adolescents: Findings from the national longitudinal study of adolescent health. Perspectives on Sexual and Reproductive Health. 2005; 37:125-134. [PubMed: 16150660]

Cunradi CB. Neighborhoods, alcohol outlets and intimate partner violence: Addressing research gaps in explanatory mechanisms. International Journal of Environmental Research and Public Health. 2010; 7:799-813. [PubMed: 20617004]

Cunradi CB, Caetano R, Clark C, Schafer J. Neighborhood poverty as a predictor of intimate partner violence among White, Black, and Hispanic couples in the United States: A multilevel analysis. Annals of Epidemiology. 2000; 10:297-308. [PubMed: 10942878]

Cunradi CB, Mair C, Ponicki W, Remer L. Alcohol outlets, neighborhood characteristics, and intimate partner violence: Ecological analysis of a California City. Journal of Urban Health-Bulletin of the New York Academy of Medicine. 2011; 88:191-200. [PubMed: 21347557]

Foran HM, O'Leary KD. Alcohol and intimate partner violence: A meta-analytic review. Clinical Psychology Review. 2008; 28:1222-1234. [PubMed: 18550239]

Freisthler B, Lery B, Gruenewald PJ, Chow J. Methods and challenges of analyzing spatial data for social work problems: The case of examining child maltreatment geographically. Social Work Research. 2006; 30:198-210.

Gomez AM. Testing the cycle of violence hypothesis: Child abuse and adolescent dating violence as predictors of intimate partner violence in young adulthood. Youth \& Society. 2011; 43:171-192.

Gorman DM, Labouvie EW, Speer PW, Subaiya AP. Alcohol availability and domestic violence. American Journal of Drug and Alcohol Abuse. 1998; 24:661-673. [PubMed: 9849776]

Gover AR, Kaukinen C, Fox KA. The relationship between violence in the family of origin and dating violence among college students. Journal of Interpersonal Violence. 2008; 23:1667-1693. [PubMed: 18349342]

Graham K, Bernards S, Wilsnack SC, Gmel G. Alcohol may not cause partner violence but it seems to make it worse: A cross national comparison of the relationship between alcohol and severity of partner violence. Journal of Interpersonal Violence. 2011; 26:1503-1523. [PubMed: 20522883]

Gruenewald PJ. The spatial ecology of alcohol problems: Niche theory and assortative drinking. Addiction. 2007; 102:870-878. [PubMed: 17523980]

Gruenewald PJ, Freisthler B, Remer L, LaScala EA, Treno A. Ecological models of alcohol outlets and violent assaults: Crime potentials and geospatial analysis. Addiction. 2006; 101:666-677. [PubMed: 16669900]

Gruenewald PJ, Freisthler B, Remer L, Lascala EA, Treno AJ, Ponicki WR. Ecological associations of alcohol outlets with underage and young adult injuries. Alcoholism, Clinical and Experimental Research. 2010; 34:519-527.

Gruenewald, PJ.; Millar, AB.; Ponicki, WR.; Brinkley, G. Physical and economic access to alcohol: The application of geostatistical methods to small area analyses in a community setting. In: Wilson, RA.; Dufour, MC., editors. The epidemiology of alcohol problems in small geographic areas. Bethesda, MD: National Institute on Alcohol Abuse and Alcoholism; 2000. p. 163-212.

Gruenewald PJ, Millar AB, Roeper P. Access to alcohol: Geography and prevention for local communities. Alcohol Health \& Research World. 1996; 20:244-251.

Gruenewald PJ, Remer L. Changes in outlet densities affect violence rates. Alcoholism: Clinical and Experimental Research. 2006; 30:1184-1193.

Harris KM, Halpern CT, Whitsel E, Hussey J, Tabor J, Entzel P, Udry JR. The national longitudinal study of adolescent health: Research design. 2009 Retrieved from http://www.cpc.unc.edu/ projects/addhealth/design.

Heyman RE, Slep AMS. Do child abuse and interparental violence lead to adulthood family violence? Journal of Marriage and the Family. 2002; 64:864-870.

Krieger N, Chen JT, Waterman PD, Rehkopf DH, Subramanian SV. Race/ethnicity, gender, and monitoring socioeconomic gradients in health: A comparison of area-based socioeconomic measures-The public health disparities geocoding project. American Journal of Public Health. 2003; 93:1655-1671. [PubMed: 14534218]

Livingston M. Alcohol outlet density and assault: A spatial analysis. Addiction. 2008; 103:619-628. [PubMed: 18339106] 
Livingston M. The ecology of domestic violence: The role of alcohol outlet density. Geospatial Health. 2010; 5(1):139-149. [PubMed: 21080328]

Livingston M. A longitudinal analysis of alcohol outlet density and domestic violence. Addiction. 2011; 106:919-925. [PubMed: 21205052]

McKinney CM, Caetano R, Harris TR, Ebama MS. Alcohol availability and intimate partner violence among US couples. Alcoholism, Clinical and Experimental Research. 2009; 33:169-176.

McKinney CM, Caetano R, Rodriguez LA, Okoro N. Does alcohol involvement increase the severity of intimate partner violence? Alcoholism-Clinical and Experimental Research. 2010; 34:655-658.

Millar AB, Gruenewald PJ. Use of spatial models for community program evaluation of changes in alcohol outlet distribution. Addiction. 1997; 92(Suppl. 2):S273-S283. [PubMed: 9231450]

Muthén, LK.; Muthén, BO. Mplus User's Guide. 6th Edition. Los Angeles, CA: Muthén \& Muthén; 1998-2010.

National Institute Standards and Technology. Auxillary. In: National Institute Standards and Technology. , editor. Data plot reference manual. Gaithersburg, MD: Author; 2007. Retrieved from http://itl.nist.gov/div898/software/dataplot/refman2/auxillar/homepage.htm

Popova S, Giesbrecht N, Bekmuradov D, Patra J. Hours and days of sale and density of alcohol outlets: Impacts on alcohol consumption and damage: A systematic review. Alcohol \& Alcoholism. 2009; 44:500-516. [PubMed: 19734159]

Sampson RJ, Raudenbush SW, Earls F. Neighborhoods and violent crime: A multilevel study of collective efficacy. Science. 1997; 277:918-924. [PubMed: 9252316]

Schonlau M, Scribner R, Farley TA, Theall KP, Bluthenthal RN, Scott M, Cohen DA. Alcohol outlet density and alcohol consumption in Los Angeles county and southern Louisiana. Geospatial Health. 2008; 3(1):91-101. [PubMed: 19021112]

Scribner RA, Cohen D, Kaplan S, Allen SH. Alcohol availability and homicide in New Orleans: Conceptual considerations for small area analysis of the effect of alcohol outlet density. Journal of Studies on Alcohol. 1999; 60:310-316. [PubMed: 10371257]

Swisher, RR. Wave III Contextual Database Codebook, Part 1. Chapel Hill, NC: University of North Carolina at Chapel Hill: Carolina Population Center; 2008.

Thompson MP, Kingree JB. The roles of victim and perpetrator alcohol use in intimate partner violence outcomes. Journal of Interpersonal Violence. 2006; 21:163-177. [PubMed: 16368759]

U.S. Dept of Commerce Bureau of the Census. Geographic areas reference manual. Washington, DC: U.S. Bureau of the Census; 1994.

\section{Biographies}

Martha W. Waller, $\mathrm{PhD}$, is associate research scientist at the Pacific Institute for Research and Evaluation (PIRE). She received her doctorate in maternal and child health from the University of North Carolina at Chapel Hill, School of Public Health in 2005. Her research interests include adolescent and young adult risk behavior and protective factors, program evaluation, trajectories of sexual identity/orientation, and use of environmental prevention strategies to reduce alcohol, tobacco and other drugs (ATOD) use among youth and adults.

Bonita J. Iritani, MA, is an associate research scientist at the Pacific Institute for Research and Evaluation (PIRE). Her research work is on risk for and prevention of HIV and sexually transmitted infections among adolescents and young adults.

Sharon L. Christ, PhD, is an assistant professor of child development and family studies and statistics at Purdue University. Her statistical research focuses on estimation of complex sample data in structural equation models and mixed effects models. Her substantive research focuses on the effects of child maltreatment on adolescent development.

Heddy Kovach Clark, $\mathrm{PhD}$, is an associate research scientist at the Pacific Institute for Research and Evaluation in Chapel Hill, North Carolina. Her research interests include 
program evaluation, prevention of child and adolescent risk behaviors, mental health, and professional development.

Kathryn E. Moracco, $\mathrm{PhD}$, is a research associate professor of health behavior and health education at the Gillings School of Global Public Health at the University of North Carolina at Chapel Hill. She conducts research on the primary and secondary prevention of violence, primarily gender-based violence. Her work is focused on evaluating violence prevention programs and policies while simultaneously building the capacity of stakeholders to design and evaluate their own interventions.

Carolyn Tucker Halpern, $\mathrm{PhD}$, is an associate professor of maternal and child health at the Gillings School of Global Public Health at the University of North Carolina at Chapel Hill. She received her $\mathrm{PhD}$ in developmental psychology from the University of Houston. Her research centers on adolescent social development and reproductive health, especially biopsychosocial models of sexual and romantic relationships, and their implications for the transition to adulthood.

Robert L. Flewelling, PhD, is a senior research scientist at the Pacific Institute for Research and Evaluation. His research interests and experience focus primarily on epidemiological studies of substance abuse and related health risk behaviors, evaluation of school- and community-based prevention strategies, state and community needs assessment studies, and the application of research findings to prevention system development and planning. 


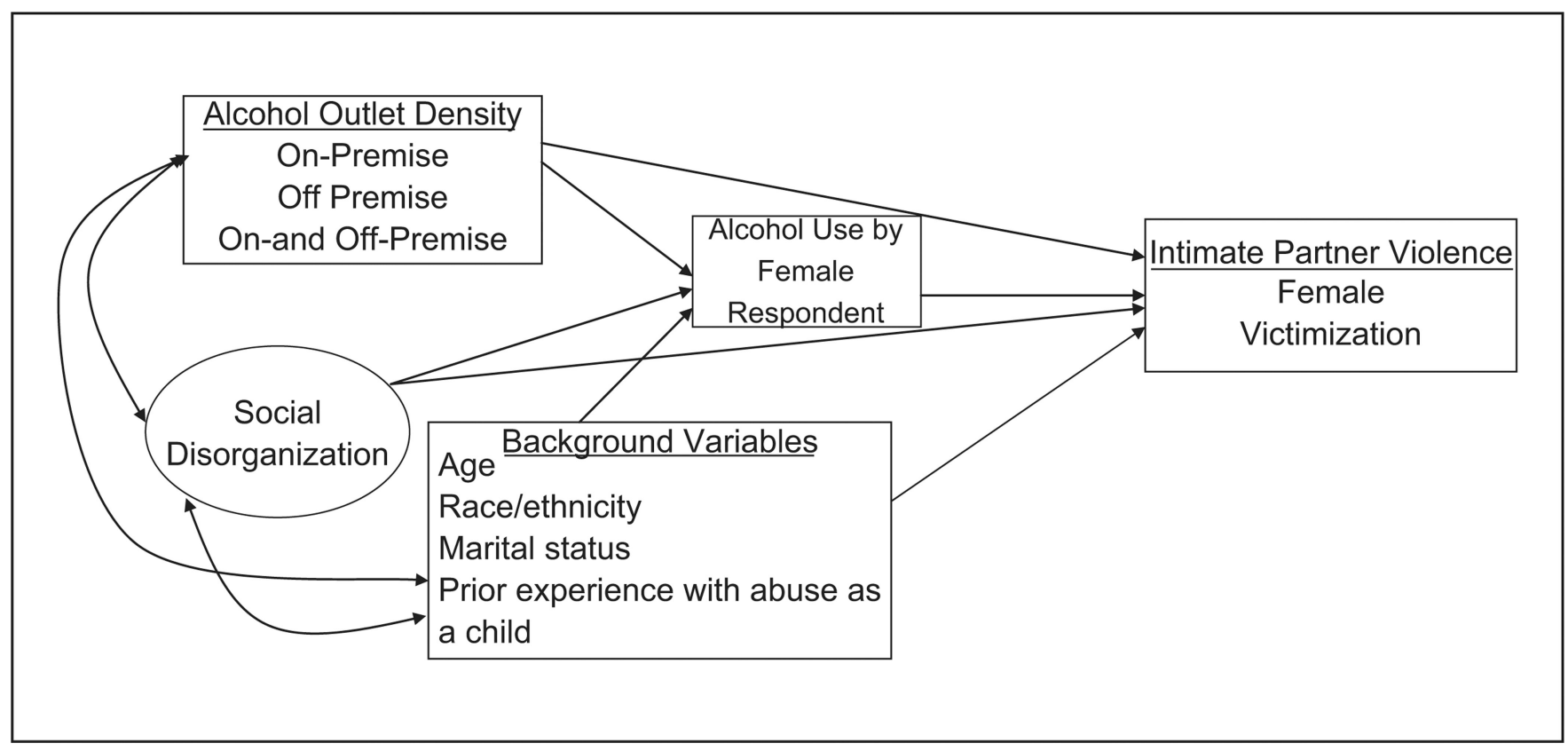

Figure 1.

Conceptual model examining the relationships between alcohol availability, alcohol consumption, and intimate partner violence and related mediating and moderating effects 
Table 1

\section{Alcohol Use Categories}

\begin{tabular}{ll}
\hline Category & Description \\
\hline $\begin{array}{l}\text { 1= Lifetime abstainers or } \\
\text { ex-drinkers }\end{array}$ & $\begin{array}{l}\text { Lifetime abstainers: respondents who reported never drinking alcohol during adolescence, never drinking alcohol } \\
\text { as an adult, and not drinking in the past } 12 \text { months. } \\
\text { Ex-drinkers: respondents who at Wave } 1 \text { and/or Wave } 3 \text { indicated they drank alcohol but have not drunk any } \\
\text { alcohol in the past } 12 \text { months. }\end{array}$ \\
$\begin{array}{l}\text { Respondents who report drinking in the past } 12 \text { months but have only } 1 \text { or } 2 \text { drinks at a time and have never been } \\
\text { drunk and never engaged in binge drinking. }\end{array}$ \\
$\begin{array}{l}\text { Respondents who report drinking in the past } 12 \text { months (typically drinking } 3 \text { or more drinks at a time), but have } \\
\text { never been drunk, and never engaged in binge drinking. }\end{array}$ \\
$\begin{array}{l}\text { Respondents who report drinking infrequently (3 to } 12 \text { times) in the over the past } 12 \text { months but report being } \\
\text { drinkers }\end{array}$ \\
$\begin{array}{l}\text { drunk and/or binge drinking. } \\
\text { drinkers }\end{array}$ \\
$\begin{array}{l}\text { Respondents who report drinking more frequently ( } 2 \text { or } 3 \text { days a month up to } 1 \text { to } 2 \text { days a week) over the past } 12 \\
\text { months and have been drunk and/or engaged in binge drinking. } \\
\text { drinkers }\end{array}$
\end{tabular}


Table 2

Characteristics of the Sample

\begin{tabular}{|c|c|}
\hline Characteristic & $\begin{array}{r}\text { Weighted \% or } \\
\text { Mean (Standard } \\
\text { Error) }\end{array}$ \\
\hline \multicolumn{2}{|l|}{ Victim of intimate partner violence } \\
\hline No IPV victimization & 80.38 \\
\hline Physical IPV only & 13.26 \\
\hline Sexual IPV only or physical and sexual IPV & 6.36 \\
\hline \multicolumn{2}{|l|}{ Alcohol use } \\
\hline Lifetime abstainer or ex-drinker & 27.07 \\
\hline Light drinker & 14.62 \\
\hline Moderate drinker & 6.64 \\
\hline Infrequent heavy drinker & 18.83 \\
\hline Occasional heavy drinker & 28.18 \\
\hline Frequent heavy drinker & 4.67 \\
\hline \multicolumn{2}{|l|}{ Age in years } \\
\hline $18-20$ & 29.01 \\
\hline 21 & 16.10 \\
\hline 22 & 18.20 \\
\hline 23 & 15.21 \\
\hline $24-27$ & 21.47 \\
\hline \multicolumn{2}{|l|}{ Race/ethnicity } \\
\hline Hispanic & 10.62 \\
\hline NonHispanic White & 70.81 \\
\hline NonHispanic Black & 14.29 \\
\hline Asian & 3.29 \\
\hline American Indian & 1.00 \\
\hline \multicolumn{2}{|l|}{ Marital status } \\
\hline Never been married to or lived with this partner & 40.75 \\
\hline Ever lived with this partner but never married to him or her & 31.20 \\
\hline Ever married to this partner & 28.05 \\
\hline Neglected as a child (percent yes) & 37.81 \\
\hline Sexually abused as a child (percent yes) & 4.43 \\
\hline Physically abused as a child (percent yes) & 26.33 \\
\hline \multicolumn{2}{|l|}{ Neighborhood characteristics } \\
\hline High alcohol outlet density (proportion yes) & 9.10 \\
\hline Alcohol outlets per square kilometer (mean) & $3.00(0.35)$ \\
\hline Proportion of population in poverty, standardized (mean) & $-0.26(0.96)$ \\
\hline Transience index, standardized (mean) & $-0.43(0.96)$ \\
\hline Proportion of population foreign-born (mean) & $0.09(0.01)$ \\
\hline Vacant housing (mean) & $0.08(0.00)$ \\
\hline
\end{tabular}

J Interpers Violence. Author manuscript; available in PMC 2013 July 01. 
Note: Based on the sample of $n=4,432$ young adult women surveyed at Wave III in the national probability sample with at least one reported current relationship, nonmissing data on the present study's IPV victimization and alcohol use variables, and whose index relationship was not same sex. 


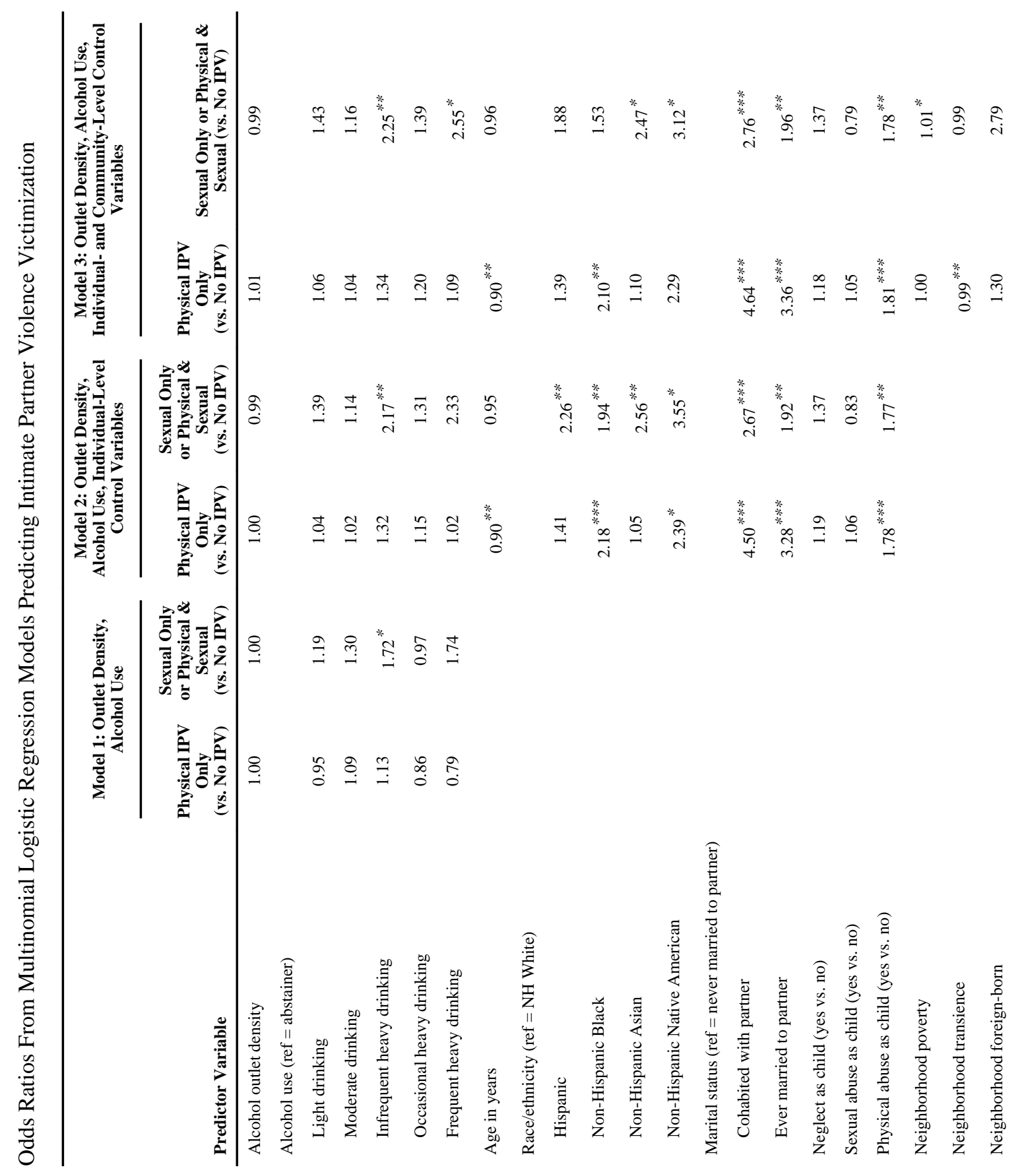




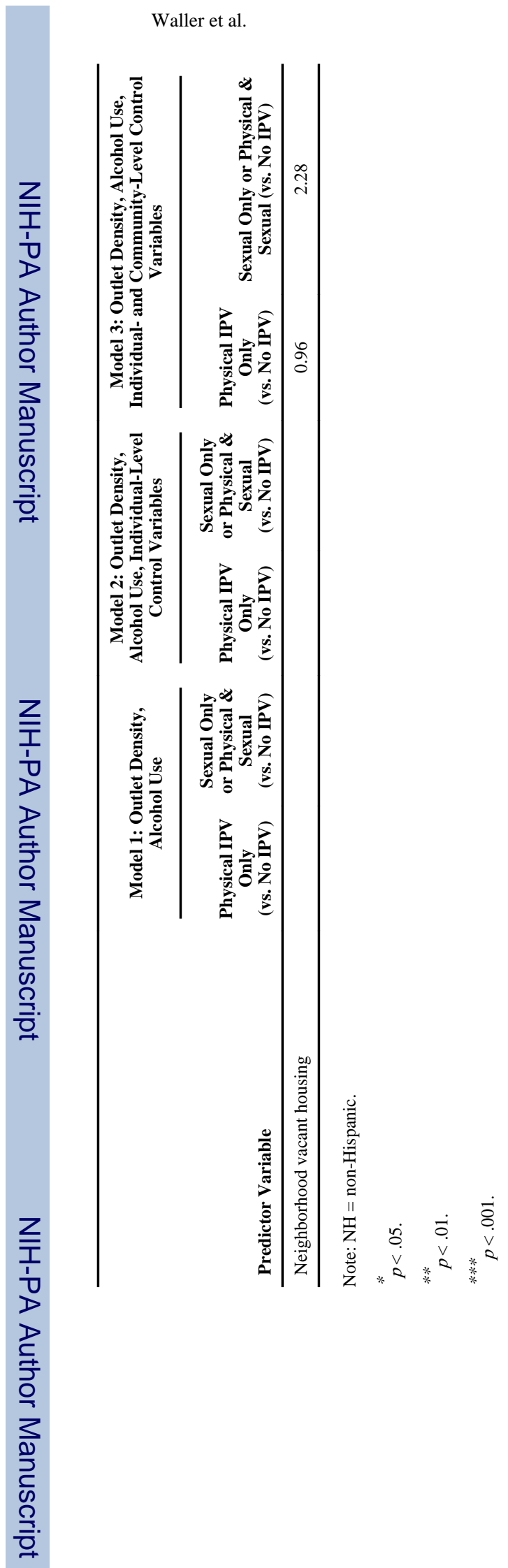

J Interpers Violence. Author manuscript; available in PMC 2013 July 01. 